\title{
Long-Term Effects of Multiwalled Carbon Nanotubes and Graphene on Microbial Communities in Dry Soil
}

\author{
Yuan Ge, ${ }^{\dagger,}, \S, \|$ John H. Priester, ${ }^{\ddagger, \S, \|}$ Monika Mortimer, ${ }^{\ddagger, \S, \|, \#}$ Chong Hyun Chang, " Zhaoxia Ji, \\ Joshua P. Schimel, ${ }^{\S, \|, \perp}$ and Patricia A. Holden ${ }^{*}, \S, \S$ \\ ${ }^{\dagger}$ State Key Laboratory of Urban and Regional Ecology, Research Center for Eco-Environmental Sciences, Chinese Academy of \\ Sciences, Beijing 100085, China \\ ${ }^{\ddagger}$ Bren School of Environmental Science and Management, ${ }^{\S}$ Earth Research Institute, "University of California Center for the \\ Environmental Implications of Nanotechnology (UC CEIN), ${ }^{\perp}$ Department of Ecology, Evolution and Marine Biology, University of \\ California, Santa Barbara, California 93106, United States \\ \#Laboratory of Environmental Toxicity, National Institute of Chemical Physics and Biophysics, Akadeemia tee 23, 12618 Tallinn, \\ Estonia
}

Supporting Information

ABSTRACT: Little is known about the long-term effects of engineered carbonaceous nanomaterials (ECNMs) on soil microbial communities, especially when compared to possible effects of natural or industrial carbonaceous materials. To address these issues, we exposed dry grassland soil for 1 year to $1 \mathrm{mg} \mathrm{g}^{-1}$ of either natural nanostructured material (biochar), industrial carbon black, three types of multiwalled carbon nanotubes (MWCNTs), or graphene. Soil microbial biomass was assessed by substrate induced respiration and by extractable DNA. Bacterial and fungal communities were examined by terminal restriction fragment length polymorphism (T-RFLP). Microbial activity was assessed by soil basal respiration. At day 0 , there was no treatment effect on soil DNA or T-RFLP profiles, indicating negligible interference between the amended materials and the methods for DNA extraction, quantification, and community analysis. After a 1-year exposure, compared to the no amendment control, some treatments reduced soil DNA (e.g., biochar, all three MWCNT types, and graphene; $P<0.05)$ and altered bacterial communities (e.g., biochar, carbon black, narrow MWCNTs, and graphene); however, there were no significant differences across the amended treatments. These findings suggest that ECNMs may moderately affect dry soil microbial communities but that the effects are similar to those from natural and industrial carbonaceous materials, even after 1-year exposure.

\section{INTRODUCTION}

Engineered carbonaceous nanomaterials (ECNMs) include fullerenes, graphene, and carbon nanotubes. ECNMs are structured in different shapes such as spheres, sheets, and tubes. Because of their excellent properties in tensile strength, elasticity, electrical conductivity, and sorption, ECNMs have been incorporated into diverse commercial products. These include composite bicycle frames, antifouling coatings, printed electronics, electrostatic discharge shielding, solar cells, super capacitors, and water filters. ${ }^{1-3}$ With their growing production and usage, ECNMs will be increasingly released into the environment including into soils. ${ }^{4-6}$ Soil microorganisms are pivotal in maintaining the health and services of terrestrial ecosystems. Therefore, the potential interactions between ECNMs and soil microbial communities should be understood to better assess the environmental effects of ECNMs. ${ }^{7,8}$ Further, given the extraordinary diversity of soil microbial communities, exposing natural soils to ECNMs provides a great opportunity to assess effects on many microbial taxa at once. Previous microbial monoculture laboratory studies have demonstrated ECNM effects and associated mechanisms. ${ }^{9-11}$ By examining ECNM effects in soil exposures, it can be determined if potential effects extrapolate across many taxa.

However, results of studies regarding ECNMs' effects on microbial communities have been mixed. It has been reported that fullerenes either have no $\left(1 \mathrm{mg} \mathrm{g}^{-1}\right.$ for 180 days exposure) or subtle $\left(0.05 \mathrm{mg} \mathrm{g}^{-1}\right.$ for 14 days exposure) effects on soil microbial community composition and function. ${ }^{12,13}$ Singlewalled carbon nanotubes (SWCNTs) were reported to induce

Received: November 15, 2015

Revised: February 11, 2016

Accepted: March 10, 2016

Published: March 10, 2016 
microbial community shifts and lower soil enzymatic activities in short-term exposure experiments, although the effects were tempered by nanotube functionalization, soil carbon content, and exposure time. ${ }^{14-17}$ Multiwalled carbon nanotubes (MWCNTs) at extremely high concentrations (e.g., $\geq 5 \mathrm{mg}$ $\mathrm{g}^{-1}$ ) can alter the relative abundance of bacterial taxa and reduce soil microbial biomass, but low concentrations (e.g., $\leq 1$ $\mathrm{mg} \mathrm{g}^{-1}$ ) generally have no effects on soil respiration, enzymatic activities, and microbial community composition after shortterm exposure. ${ }^{18-20}$ Graphene showed time-dependent effects on the structure, abundance, and function of soil bacterial communities during a 60-day exposure. ${ }^{21}$ There is also limited evidence that ECNMs (e.g., fullerol and carbon nanotubes) could be transformed by enzymes produced by soil fungi and bacteria. $^{22-25}$

Despite reports thus far regarding interactions between ECNMs and soil microbial communities, some knowledge gaps still exist. First, because most ECNMs are relatively stable and appear resistant to biodegradation, ${ }^{26}$ there is a potential for long-term effects. However, little information is available to assess the long-term effects of ECNMs on soil microbial communities. 6 Second, although studies have examined the short-term effects of fullerenes, SWCNTs, and MWCNTs by comparing with ECNM-free controls, there are other natural and industrial carbonaceous materials (e.g., biochar and carbon black) that are produced in vast quantities. Given the intentional use of nanostructured biochars as potentially beneficial soil amendments, and the greater than 50-year history of widespread use of industrial carbon black (e.g., in pigments and automotive tires) - and therefore its certain entry into soils, benchmarking ECNM effects to these other common carbonaceous nano- or nanostructured materials could provide a meaningful baseline for evaluating potential ECNM ecotoxicology effects.

To compare the long-term effects of ECNMs with natural and industrial carbonaceous materials, we exposed grassland soils with their diverse indigenous microbial communities to biochar, carbon black, graphene, or three types of MWCNTs. We intentionally used soils sampled under summertime (dry) conditions, since our prior work examining how soil moisture influences the responses of the microbial community when exposed to nano- $\mathrm{TiO}_{2}$ revealed that dry conditions maximized the resolved diversity of the microbial community while allowing exposure to the particles. Thus, while incubating the soils under dry conditions limited microbial activity, it may have increased the sensitivity for detecting direct toxic effects, since dry conditions promote fragmented soil microhabitats with direct ECNM exposures. ${ }^{27}$ After 1 year of incubation, we assessed soil microbial biomass, bacterial and fungal community composition, and microbial activity to examine the comparative treatment effects. This research newly evaluates the long-term effects of ECNMs on dry soil microbial community structure and function-both of which contribute to delivering soil ecosystem services. By using biochar and carbon black as negative control materials, this study also newly benchmarks ECNM effects to materials that are chemically similar yet differ in their morphology, manufacturing method, and regulatory concern.

\section{MATERIALS AND METHODS}

Soil. Grassland soil (0-10 cm depth) was collected from the University of California Sedgwick Natural Reserve (34 $40^{\prime} 32^{\prime \prime}$ $\mathrm{N}, 120^{\circ} 2^{\prime} 27^{\prime \prime} \mathrm{W}$ ), sieved ( 4 then $2 \mathrm{~mm}$ ), then bagged, and stored at room temperature for less than 2 weeks. Because the soil was collected during the summer (dry) season, the soil was dry (water content 5\%). Sedgwick Natural Reserve soil was chosen because this soil was previously used to examine nano$\mathrm{TiO}_{2}$ and nano-ZnO effects on soil microbial communities. ${ }^{28,29}$ The water content of the soil used in this study was somewhat lower than the driest soil studied previously for interactive effects of water potential and nano- $\mathrm{TiO}_{2}$ on soil bacterial communities. $^{30}$ As reported previously, the soil is a weakly acidic ( $\mathrm{pH}$ 6.45) Pachic Argiustoll in the Botella series, with a sandy clay loam texture ( $51 \%$ sand, $27 \%$ silt, and $22 \%$ clay) containing $3.1 \% \mathrm{C}$ and $0.27 \% \mathrm{~N}^{30}$

Carbonaceous Materials. The carbonaceous materials used in this study included biochar (Blue Sky, Thousand Oaks, CA), carbon black (Printex 30, Orion Engineered Carbons, Kingwood, TX), three types of as-prepared MWCNTs, and graphene (Cheap Tubes, Grafton, VT). As a beneficial soil amendment produced from the pyrolytic conversion of plant biomass, biochar was used as a natural carbonaceous material control. Carbon black was used as an industrial carbonaceous nanomaterial control due to its longstanding application in pigments and automotive tires, as reflected by its highest production quantities among manufactured nanomaterials (i.e., over $1 \mathrm{E} 7$ tons per year). ${ }^{31}$ From an environmental regulatory standpoint, $\mathrm{CB}$ is considered persistent yet does not meet bioaccumulation and aquatic toxicity criteria. ${ }^{32}$ Thus, CB was adopted herein as an analogous material to the tested ECNMs, yet with $\mathrm{CB}$ serving as an industrial ecotoxicological negative control. MWCNTs and graphene were chosen as representatives of ECNMs because they have been increasingly incorporated into diverse commercial products and thus have high potential for accumulation in soils. $1,4,33$

Besides the properties provided by the materials' suppliers, we characterized some selected material properties that may affect ECNM effects on soil microbial communities. Environmental scanning electron microscopy (ESEM), scanning electron microscopy (SEM, ZEISS SUPRA 40VP), or transmission electron microscopy (TEM, JEOL 1200 EX, acceleration voltage $80 \mathrm{kV}$ ) was used to visualize material morphology. Specific surface area (SSA) was measured by Brunauer-Emmett-Teller (BET) analysis ${ }^{34}$ using a Tristar 3000 Porosimiter (Micromeritics, Norcross, GA) and $\mathrm{N}_{2}$ as the adsorption gas. Material impurity and primary oxidation temperature (an indicator of material thermal stability) were quantified using thermogravimetric analysis (TGA) on a Mettler STARe ThermoGravimetric Analyzer (TGA/ sDTA851e, Mettler Toledo LLC, Columbus, OH). More details about the material characterizations can be found in the Supporting Information.

Exposure Experiment. Based on the evaluation of exposure concentrations in previous publications, ${ }^{31}$ a single concentration of $1 \mathrm{mg}$ amendment per $\mathrm{g}$ dry soil was selected for this study. For each microcosm, approximately $70 \mathrm{~g}$ (oven dry equivalent) of soil was placed into sterile $250 \mathrm{~mL}$ Boston amber rounds (Fisher Scientific, Tustin, CA), with $24 \mathrm{~mm}$ Mininert caps and Teflon-taped threads for gas tightness. For each, $70 \mathrm{mg}$ of dry powder amendment was weighed directly into the microcosm. Each treatment was established in triplicate. Because we aimed to maintain natural soil conditions, microcosms were established without any water addition. The sealed microcosms were rolled on a roller table for $1 \mathrm{~h}$ to mechanically homogenize dry powder nanomaterials into the soil. ${ }^{30}$ Controls without amendments were identically estab- 
lished. After mixing, microcosms were immediately subsampled, and subsamples (approximate $5 \mathrm{~g}$ for each) were denoted as 0day samples and frozen at $-80{ }^{\circ} \mathrm{C}$ for later DNA-based analyses. After day 0 sampling, microcosms were incubated at room temperature $\left(22^{\circ} \mathrm{C}\right)$ for 1 year. During the course of the exposure, periodic headspace samples were acquired for $\mathrm{CO}_{2}$ concentration analysis to indicate ongoing respiration; the bottles were also passively aerated twice (approximately $1 \mathrm{~h}$ ) to reoxygenate. After aeration, the $\mathrm{CO}_{2}$ concentrations in the bottle headspaces decreased to atmospheric levels, indicating that the aeration process was sufficient. After a 1-year exposure, microcosms were destructively subsampled for end point analyses.

Soil Basal Respiration (SBR). SBR was measured periodically during the 1-year incubation to evaluate treatment effects on soil microbial activity. The $\mathrm{CO}_{2}$ concentration in microcosm headspace gas was measured using the same method as described below for the SIR $\mathrm{CO}_{2}$ measurement.

Substrate Induced Respiration (SIR). SIR was measured at the conclusion of the exposure experiment to evaluate treatment effects on soil microbial biomass. SIR measures potential respiration (a function of biomass) after adding saturating levels of labile carbon. ${ }^{35,36}$ For each measurement, approximately $20 \mathrm{~g}$ of dry soil was mixed with $20 \mathrm{~mL}$ of sterile yeast extract solution $(1.2 \%, \mathrm{w} / \mathrm{w})$ in a $250 \mathrm{~mL}$ Boston amber round and incubated at room temperature $\left(22^{\circ} \mathrm{C}\right)$ for $4 \mathrm{~h} . \mathrm{CO}_{2}$ increases in bottle headspace were sampled $(5 \mathrm{~mL})$ at 2 -h intervals using a $5 \mathrm{~mL}$ luer lock syringe through the Mininert cap and measured using an infrared analyzer (EGM-4; PP Systems, Amesbury, MA).

Soil DNA Extraction and Quantification. For the 0-day and the 1-year samples, soil DNA was extracted from $0.3 \mathrm{~g}$ of soil using the Powersoil DNA Isolation Kit (Mo Bio, Carlsbad, CA) following the manufacturer's instruction. The total extractable soil DNA was used as another index of microbial biomass. $^{28,37,38}$ Soil DNA was quantified using two independent methods: the Nanodrop and the Quant-iT DNA Assay Kit. For the Nanodrop method, DNA concentration was determined based on the absorbance at the wavelength of $260 \mathrm{~nm}$ using a spectrophotometer (Nanodrop, Wilmington, DE). For the Quant-iT DNA Assay Kit, DNA concentration was measured based on the emitting fluorescence (a function of the amount of dsDNA) after adding the dsDNA-specific fluorophore (Alexa Fluor 488 dye, Quant-iT DNA Assay Kit, High Sensitivity, Invitrogen, Eugene, OR). The fluorescence intensity was measured using a Synergy Multi-Mode Microplate Reader (Biotek, Winooski, VT) with excitation/emission wavelengths of 485 and $528 \mathrm{~nm}$, respectively. The Quant-iT DNA Assay Kit is a more sensitive method for DNA quantification than the Nanodrop method, since the former is highly selective for dsDNA and insensitive to common contaminants such as salts, solvents, detergents, or protein.

Bacterial and Fungal Community Analyses. Bacterial and fungal communities were analyzed by polymerase chain reaction (PCR) followed by terminal restriction fragment length polymorphism (T-RFLP). In brief, the extracted DNA was used as a template to amplify genes encoding bacterial $16 \mathrm{~S}$ rRNA and fungal internal transcribed spacer (ITS) regions. The primers used for bacterial PCR were HEX-labeled 8F (AGA GTT TGA TCC TGG CTC AG) and 1492R (GGT TAC CTT GTT ACG ACT T). ${ }^{39,40}$ The primers used for fungal PCR were FAM-labeled ITS1F (CTT GGT CAT TTA GAG GAA GTA A) and ITS4R (TCC TCC GCT TAT TGA TAT
GC). ${ }^{16,41}$ Each $0.5 \mathrm{~mL}$ reaction tube contained $50 \mu \mathrm{L}$ of reaction mixture, containing $1 \times$ PCR buffer, $2.5 \mathrm{mM} \mathrm{MgCl}$, $0.2 \mathrm{mM}$ of each dNTP, $0.2 \mu \mathrm{M}$ of each primer, $1.5 \mathrm{U}$ GoTaq DNA Polymerase (Promega, Madison, WI), $0.2 \mu \mathrm{g} \mu \mathrm{L}^{-1}$ bovine serum albumin (BSA), and $10 \mathrm{ng}$ of template DNA. The PCR was performed using a Sprint Thermal Cycler (Thermo Scientific, Lafayette, CO). The thermal cycling scheme for bacterial PCR was an initial denaturation at $95{ }^{\circ} \mathrm{C}$ for $5 \mathrm{~min}, 30$ cycles of denaturation at $94{ }^{\circ} \mathrm{C}$ for $45 \mathrm{~s}$, annealing at $57^{\circ} \mathrm{C}$ for $60 \mathrm{~s}$ and extension at $72{ }^{\circ} \mathrm{C}$ for $2 \mathrm{~min}$, and a final extension step at $72{ }^{\circ} \mathrm{C}$ for $7 \mathrm{~min}$. The thermal cycling scheme for fungal PCR was an initial denaturation at $95{ }^{\circ} \mathrm{C}$ for $5 \mathrm{~min}, 30$ cycles of denaturation at $95{ }^{\circ} \mathrm{C}$ for $30 \mathrm{~s}$, annealing at $55^{\circ} \mathrm{C}$ for $30 \mathrm{~s}$ and extension at $72{ }^{\circ} \mathrm{C}$ for $60 \mathrm{~s}$, and a final extension step at $72{ }^{\circ} \mathrm{C}$ for $10 \mathrm{~min}$. For each sample, triplicate PCR products were pooled to reduce random PCR bias. After size and quality verification by $1.2 \%$ agarose gel electrophoresis (Flashgel DNA system; Lonza, Allendale, NJ), PCR products were purified using the QIAquick PCR Purification Kit (Qiagen, Valencia, CA) and quantified using the Quant-iT DNA Assay Kit (Invitrogen, Eugene, OR).

For T-RFLP, the purified bacterial PCR products were digested using the HhaI restriction enzyme (Promega, Madison, WI $) ;{ }^{27,42}$ the purified fungal PCR products were digested using either HhaI or MspI restriction enzymes (Promega, Madison, WI). ${ }^{16,41}$ The digested PCR products were shipped to the DNA Sequencing Facility at the University of California, Berkeley (http://mcb.berkeley.edu/barker/ dnaseq) for T-RFLP analysis using a 3730xl DNA Analyzer (Applied Biosystems, Foster, CA). T-RFLP profiles were aligned using the crosstab Excel macro "treeflap", ${ }^{43}$ and only the fragments between 50 and 500 bp in size with peak heights greater than $1 \%$ were included in the alignment. The relative abundance data, defined as the peak height proportions of specific restriction fragments in a whole community, were used to explore the response patterns of the overall community.

Statistical Analysis. After testing the normality and variance homogeneity, one-way analysis of variance (ANOVA) was performed to test the treatment effects on SIR and DNA-based analyses. Where the global treatment effect was significant $(P<0.05)$, a Tukey's test was performed to test the significance $(\alpha=0.05)$ for pairwise comparisons. Repeated measures ANOVA was conducted to test the treatment effects on SBR since respiration was measured repeatedly over 1 year. Principal coordinates analysis (PCoA), an unconstrained ordination technique, was performed to examine the Bray-Curtis distances between T-RFLP profiles and thus to explore treatment effects on microbial communities. PCoA uses a linear mapping of the distance between objects (e.g., Bray-Curtis distance between samples) onto twodimensional ordination space, and the algorithm attempts to preserve most of the variance in the original data set. The treatment effects on microbial communities were also tested by the direct comparisons of community dissimilarities (BrayCurtis distance) using the Student's $t$ test. A Mantel test with 9999 permutations was used to test the correlation between two T-RFLP profiles derived from HhaI- and MspI-digested fungal PCR products. The Mantel test calculates a correlation between the two distance matrices (e.g., Bray-Curtis distance matrices) and assesses the test significance based on permutations of the objects in one of the matrices. Analyses were conducted using either R (http://www.r-project.org/), 

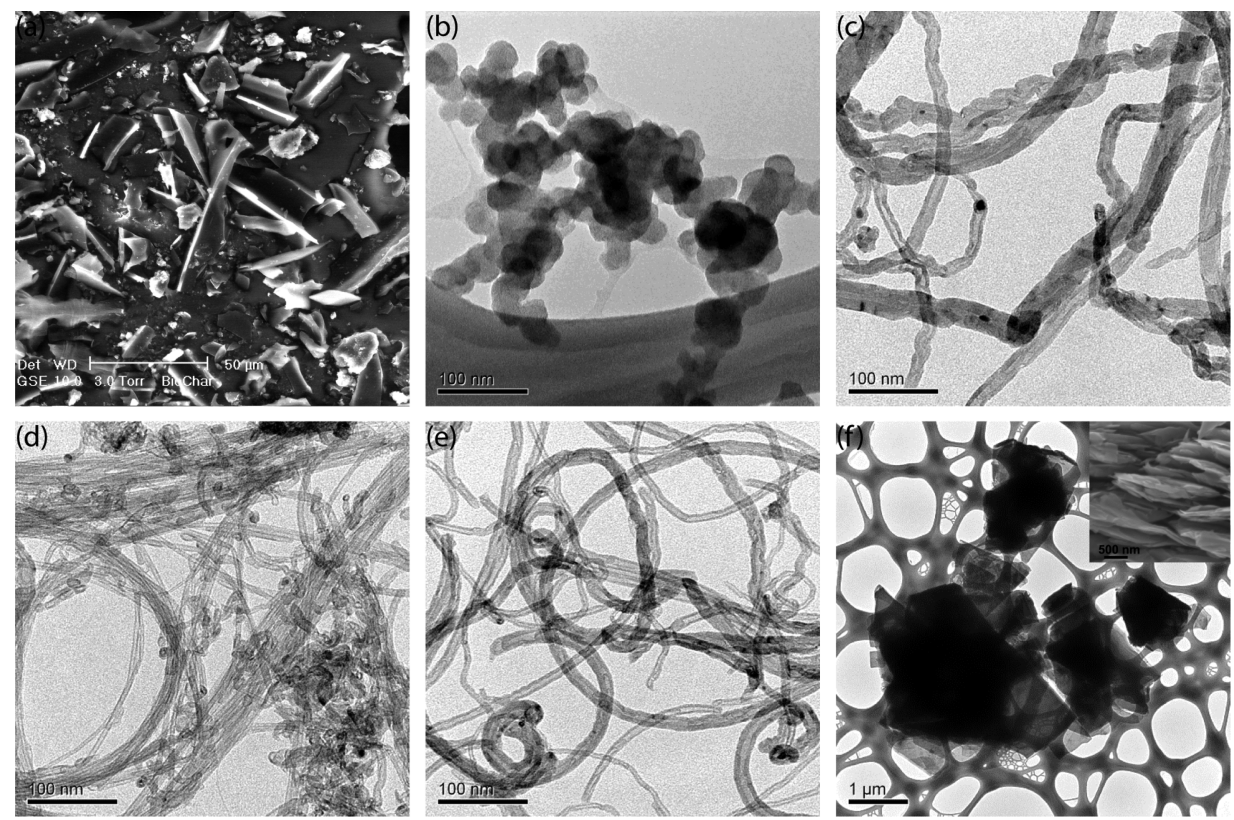

Figure 1. Environmental scanning electron microscope (ESEM, a), transmission electron microscope (TEM, b-f), or scanning electron microscope (SEM, f insert) images of the materials used in this study: (a) biochar; (b) carbon black; (c) MWCNT-1 (wide MWCNTs with specific surface area of $60 \mathrm{~m}^{2} \mathrm{~g}^{-1}$ ); (d) MWCNT-2 (narrow MWCNTs with specific surface area of $500 \mathrm{~m}^{2} \mathrm{~g}^{-1}$ ); (e) MWCNT-3 (intermediate MWCNTs with specific surface area of $200 \mathrm{~m}^{2} \mathrm{~g}^{-1}$ ); (f) graphene ( $\mathrm{f}$ insert, SEM image to show the thickness of graphene with multiple layers).

SPSS (SPSS, Chicago, USA), or CANOCO (Microcomputer Power, Ithaca, USA).

\section{RESULTS AND DISCUSSION}

Material Characterization. To systemically study longterm effects of carbonaceous nanostructured or nanoscaled materials on soil microbial communities, we established a library including natural (biochar), industrial (carbon black), and engineered carbonaceous nanomaterials (three MWCNTs and graphene). The materials varied substantially in morphology (by ESEM, TEM, and SEM; Figure 1) and other properties including diameter (by TEM), impurity (by TGA), SSA (by BET analysis), and primary oxidation temperature (by TGA; Table 1). For example, the studied set of ECNMs included

Table 1. Material Properties Characterized in This Study

\begin{tabular}{lllcl}
\multicolumn{1}{c}{ material } & diameter $(\mathrm{nm})$ & $\begin{array}{c}\text { impurity } \\
(\mathrm{wt} \%)^{a}\end{array}$ & $\begin{array}{c}\text { specific } \\
\text { surface area } \\
\left(\mathrm{m}^{2} \mathrm{~g}^{-1}\right)\end{array}$ & $\begin{array}{c}\text { primary } \\
\text { oxidation } \\
\text { temp }\left({ }^{\circ} \mathrm{C}\right)\end{array}$ \\
biochar & $\mathrm{N} / \mathrm{A}$ & 7.2 & 300 & 462 \\
carbon black & $36.6 \pm 8.3$ & $0.56 \pm 2.0$ & 72 & $611 \pm 13$ \\
MWCNT-1 & $23.3 \pm 5.5$ & $1.9 \pm 2.7$ & 60 & $610 \pm 1.1$ \\
MWCNT-2 & $7.4 \pm 1.9$ & $6.9 \pm 0.1$ & 500 & $495 \pm 22$ \\
MWCNT-3 & $13.6 \pm 4.6$ & $2.4 \pm 2.0$ & 200 & $516 \pm 6.3$ \\
graphene & $2415 \pm 983^{b}$ & $0.58 \pm 0.4$ & 70 & $688 \pm 22$
\end{tabular}

${ }^{a}$ Impurity indicates noncarbon content. ${ }^{b}$ This is the average length of graphene sheet.

wide MWCNTs (MWCNT-1) with a SSA of $60 \mathrm{~m}^{2} \mathrm{~g}^{-1}$, narrow MWCNTs (MWCNT-2) with a SSA of $500 \mathrm{~m}^{2} \mathrm{~g}^{-1}$, and intermediate MWCNTs (MWCNT-3) with a SSA of $200 \mathrm{~m}^{2}$ $\mathrm{g}^{-1}$. When comparing the measured properties of ECNMs with the values reported by the manufacturer (Cheap Tubes, Table S1), the diameters of MWCNT-2 and MWCNT-3 were slightly different. However, the widest MWCNTs $(23.3 \mathrm{~nm})$ were distinctly thinner than the manufacturer's reported value (30-
$50 \mathrm{~nm})$. We were unable to obtain any detailed length information from the SEM images but could confirm that MWCNT- 3 contained a large amount of short tubes $(1-2 \mu \mathrm{m})$. The measured impurities of MWCNT- 1 and MWCNT- 3 were within range of the manufacturer's reported values, while the impurities of MWCNT-2 (6.9\%) exceeded the reported values $(<5 \%)$. The TGA results were used to convert the nominal mass for each amendment ( $1 \mathrm{mg}$ per $\mathrm{g}$ dry soil) to a $\mathrm{C}$ massbasis. Thus, the amount of carbon added in $1 \mathrm{~g}$ of dry soil was $0.93 \mathrm{mg}$ for biochar, $0.99 \mathrm{mg}$ for carbon black, $0.98 \mathrm{mg}$ for MWCNT-1, $0.93 \mathrm{mg}$ for MWCNT-2, $0.98 \mathrm{mg}$ for MWCNT-3, and $0.99 \mathrm{mg}$ for graphene, respectively.

Soil Microbial Biomass. Soil DNA and substrate induced respiration (SIR) were used to evaluate the treatment effects on soil microbial biomass. With DNA-based microbial biomass assessments, it is possible that amended nanomaterials could interfere with DNA extraction and quantification. ${ }^{44,45}$ If this is true, the observed treatment effects may only reflect nanomaterial effects on DNA extraction and quantification methods, rather than on soil microbial biomass. Therefore, before using soil DNA as an indicator to evaluate nanomaterial effects on microbial biomass, the method was validated to exclude the former possibility. To do that, besides the postexposure soils, we also extracted and quantified soil DNA when the materials were just mixed with soils (0-day exposure). There were no significant treatment effects on soil DNA at day $0(P>0.6$ using either the Nanodrop method or the Quant-iT DNA Assay Kit, Figure 2a, b), indicating that the treatments did not affect soil DNA extraction and quantification. Thus, our use of extractable DNA - which was not to quantify absolute DNA amounts in the soils-was an unbiased way of comparing treatment effects on this index of biomass. Further, it has been shown previously that SIR biomass and extractable DNA are typically well correlated. ${ }^{28,46}$ In our current study, the two DNA quantification methods yielded results that were significantly well-correlated $(P<0.01)$, and there was a significant 

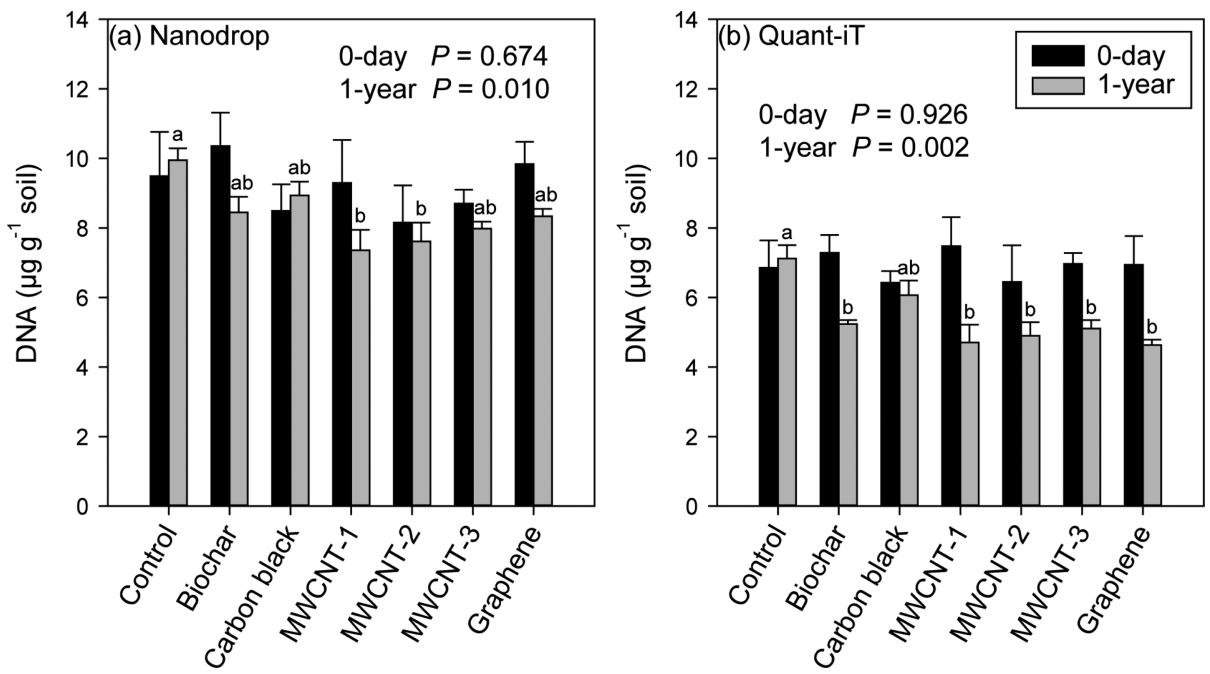

Figure 2. Treatment effects on soil DNA quantified by the Nanodrop method (a) and Quant-iT DNA Assay Kit (b) after 0-day (black bars) and 1year (gray bars) incubation. With the 0-day incubation, there was no significant treatment effect; with 1-year incubation, there was a significant treatment effect. Error bars indicate the standard error of the mean $(n=3)$. Bars labeled by the same letter do not differ at $P<0.05$.

correlation between SIR and extractable DNA $(R>0.55$, Figure S1, $P<0.01$ for both DNA quantification methods).

By SIR, there were no significant differences among treatments at the significance level of $0.05(P=0.084$, Figure 3 ) following the 1 year exposure. In contrast, soil DNA showed

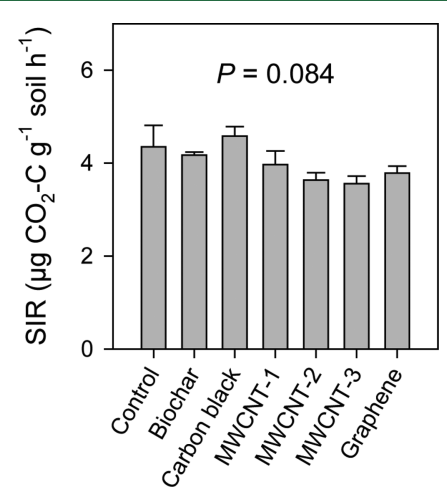

Figure 3. Treatment effects on substrate induced respiration (SIR) after 1-year of incubation. Error bars indicate the standard error of the mean $(n=3)$.

significant differences among treatments $(P<0.05$ for both Nanodrop method and Quant-iT DNA Assay Kit, Figure 2a, b). This may be because SIR is a physiological assay that responds only to live cells, ${ }^{35,36}$ while extractable DNA may reflect a timeintegrated treatment effect on microorganisms, since it may include extracellular DNA from lysed dead cells or in the extracellular polymer matrix. ${ }^{37,47,48}$

Pairwise comparisons to the no amendment control showed that carbon black did not significantly affect extractable soil DNA after 1 year exposure $(P>0.05)$, while other treatments (biochar, three MWCNTs, and graphene) significantly reduced extractable soil DNA $(P<0.05)$. However, the effects caused by the examined ECNMs (three MWCNTs, and graphene)when compared to one another in isolation of the controlwere not significantly different from the effects caused by the natural (biochar) and industrial (carbon black) carbonaceous materials $(P>0.05)$. By design, we regarded biochar as a negative control nanostructured material, since biochar is globally regarded as a beneficial soil amendment for improving soil fertility and sequestering atmospheric carbon. ${ }^{49}$ Yet, effects of biochar on soil microbial communities may be quite variable. For example, although most previous studies revealed that biochar increases soil microbial biomass, biochar effects can be moderated by soil conditions and biochar properties (e.g., parent material, pyrolytic temperature, and time), ${ }^{49,50}$ and thus a negative effect on soil microbial biomass may also be observed. ${ }^{51}$ Still, biochar is intentionally applied to soil and thus is inherently regarded as nontoxic. Overall, since microbial biomass was similar across MWCNTs, graphene, and biochar, the tested ECNMs are similarly nontoxic when compared to biochar, and thus the characteristics (Table 1) of these condensed carbon materials do not differentially affect gross microbial biomass as quantified by either SIR or extractable soil DNA, although more susceptible microorganisms may have been affected by the ECNMs, and other microorganisms may have taken their place.

The absolute amounts of DNA and SIR were indicative of low biomass. In a previous study in which soils sampled from the same Sedgwick Natural Reserve site were incubated at low water potential for nine months, ${ }^{27}$ the DNA amount extracted from the driest soil ( $7 \%$ water content) was $5.3 \pm 1.3 \mu \mathrm{g} \mathrm{g}^{-1}$. In this study, the soil was drier ( $5 \%$ water content), but the DNA amount by the Quant-iT method after a 1-year incubation was comparable (ca. 4-7 $\mu \mathrm{g} \mathrm{g}^{-1}$; Figure $2 \mathrm{~b}$ ). We did not measure SIR in the prior study ${ }^{27}$ so therefore were unable to compare SIR across the prior and current studies, but the comparison of DNA amounts indicates that the additional dryness here was not imposing a much greater effect than the driest condition in the prior study. Because soil microbial populations reside in spatially segregated microhabitat patches connected via water films in soil pores, ${ }^{52}$ varying soil water can change the size and connectivity of microhabitat patches. Thus, the dry conditions here could also promote fragmented soil microhabitats for which direct ECNM effects to microbial populations could be assessed due to enhanced exposures. Also in the previous study, ${ }^{27}$ nano- $\mathrm{TiO}_{2}$ effects on soil bacterial communities were mediated by soil water: nano- $\mathrm{TiO}_{2}$-induced community dissimilarities increased when soils became drier. With regards to soil microbial biomass, the dry conditions here appeared 

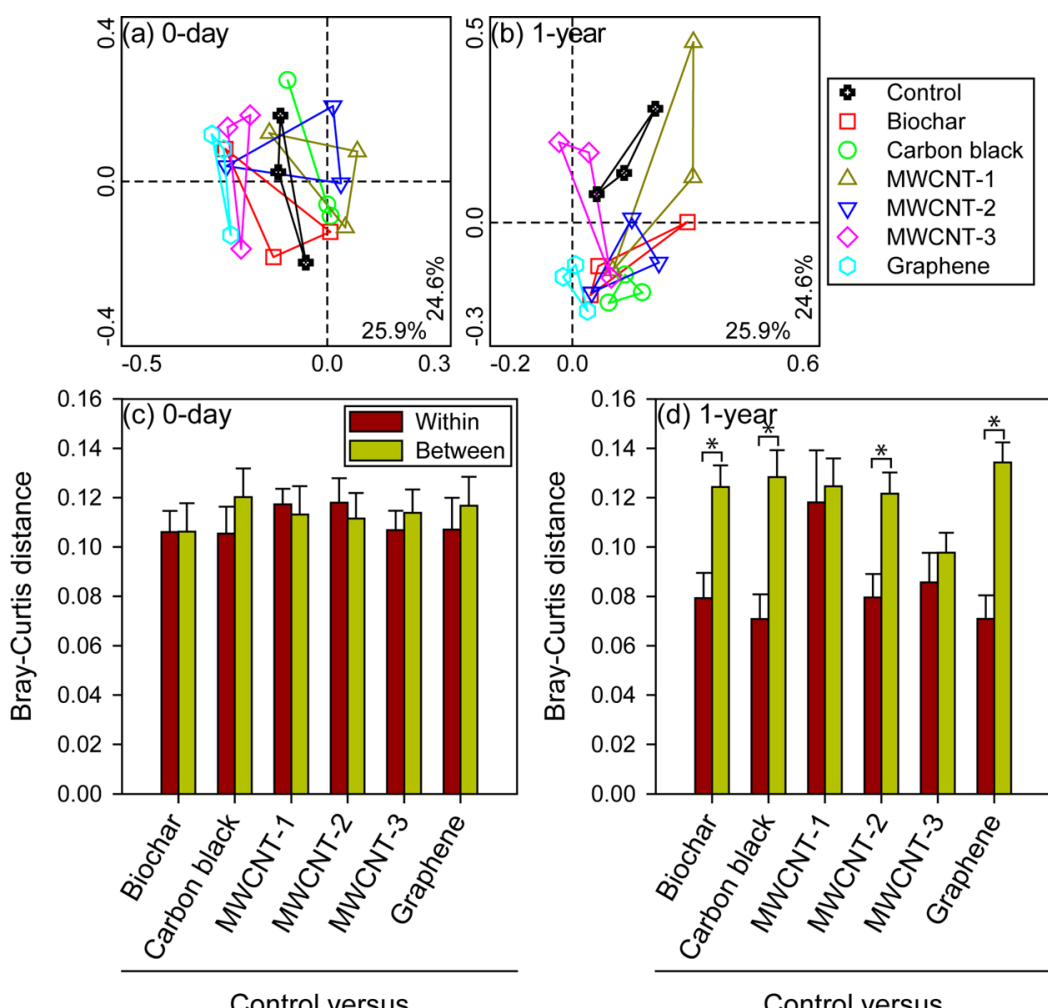

Control versus

Control versus

Figure 4. Treatment effects on soil bacterial communities analyzed by terminal restriction fragment length polymorphism (T-RFLP) using HhaI digested PCR products: (a) bacterial community variation after 0-day exposure; (b) bacterial community variation after 1-year exposure; (c) comparisons of community dissimilarities within and between treatments after 0-day exposure; (d) comparisons of community dissimilarities within and between treatments after 1-year exposure. Error bars indicate the standard error of the mean $(n=3)$. * indicates significant difference at $P<$ 0.05 .

similar to the driest condition in the prior study, ${ }^{27}$ thus suggesting that the use of dry conditions to expose many taxa at once under noncompetitive (habitat fragmentation) conditions was again accomplished without severely compromising the microbial communities.

Soil Bacterial Community. T-RFLP analysis was used to examine bacterial community profiles under different treatments. When soils were just mixed with carbonaceous materials (0-day exposure), no treatment effects on bacterial communities were observed, as reflected by the convergence of different treatments in the PCoA graph (Figure 4a). This was also suggested by the direct comparisons of community dissimilarities using the Student's $t$ test: there were no significant differences for community dissimilarities within and between treatments $(P>0.05$ for all pairs, Figure $4 c)$. Therefore, similar to what was observed for soil microbial biomass, the treatments did not affect the performance of the microbial profiling method (T-RFLP).

After 1 year, when compared to the no amendment control, bacterial communities were significantly altered by biochar, carbon black, narrow MWCNT (MWCNT-2), and graphene. The wide MWCNTs (MWCNT-1 and MWCNT-3) did not significantly change bacterial communities (Figure $4 \mathrm{~b}, \mathrm{~d}$ ). However, the effects caused by ECNMs (narrow MWCNT and graphene) were not significantly different than the effects caused by the natural (biochar) and the industrial (carbon black) carbonaceous material. These results suggest not only that the ECNM effects on soil bacterial communities may be moderated by ECNM types or properties but also that the ECNMs used in this study have no greater effect than natural or industrial carbonaceous materials such as biochar and carbon black.

Other short-term exposure experiments have shown that SWCNT effects on soil bacterial communities could be tempered by nanotube functionalization, soil conditions, exposure time, and exposure concentration. For example, Tong et al. compared the effects of as-produced and functionalized SWCNTs on soil microbial communities in two soils (low versus high organic matter) in a chronic exposure experiment for 6 weeks. They found that only the asproduced SWCNTs induced microbial community shifts and minor changes in soil metabolic activity in low organic matter soils. ${ }^{17}$ Rodrigues et al. examined the effects of functionalized SWCNTs (up to $0.5 \mathrm{mg} \mathrm{g}^{-1}$ ) on soil microbial communities in an exposure experiment for up to 14 days. They found that bacterial communities were transiently affected by functionalized SWCNTs: the major effects were observed after 3 days of exposure, but the bacterial community recovered after 14 days. ${ }^{16}$ Shrestha et al. evaluated MWCNT effects on microbial community composition and function in a sandy loam soil over 90 days. They observed no effect of MWCNTs on soil respiration, enzymatic activity, and bacterial community composition at a concentration of $\leq 1 \mathrm{mg} \mathrm{g}^{-1}$. ${ }^{20}$ However, MWCNTs at high concentration $\left(\geq 5 \mathrm{mg} \mathrm{g}^{-1}\right)$ altered the relative abundance of bacterial taxa in the community, reduced soil microbial biomass, and repressed enzyme activity. ${ }^{18,20}$

Soil Fungal Community. We also examined treatment effects on soil fungal communities, which are generally more tolerant than bacteria to desiccation ${ }^{53}$ and which have been studied for their potential to biodegrade ECNMs. ${ }^{26}$ The 


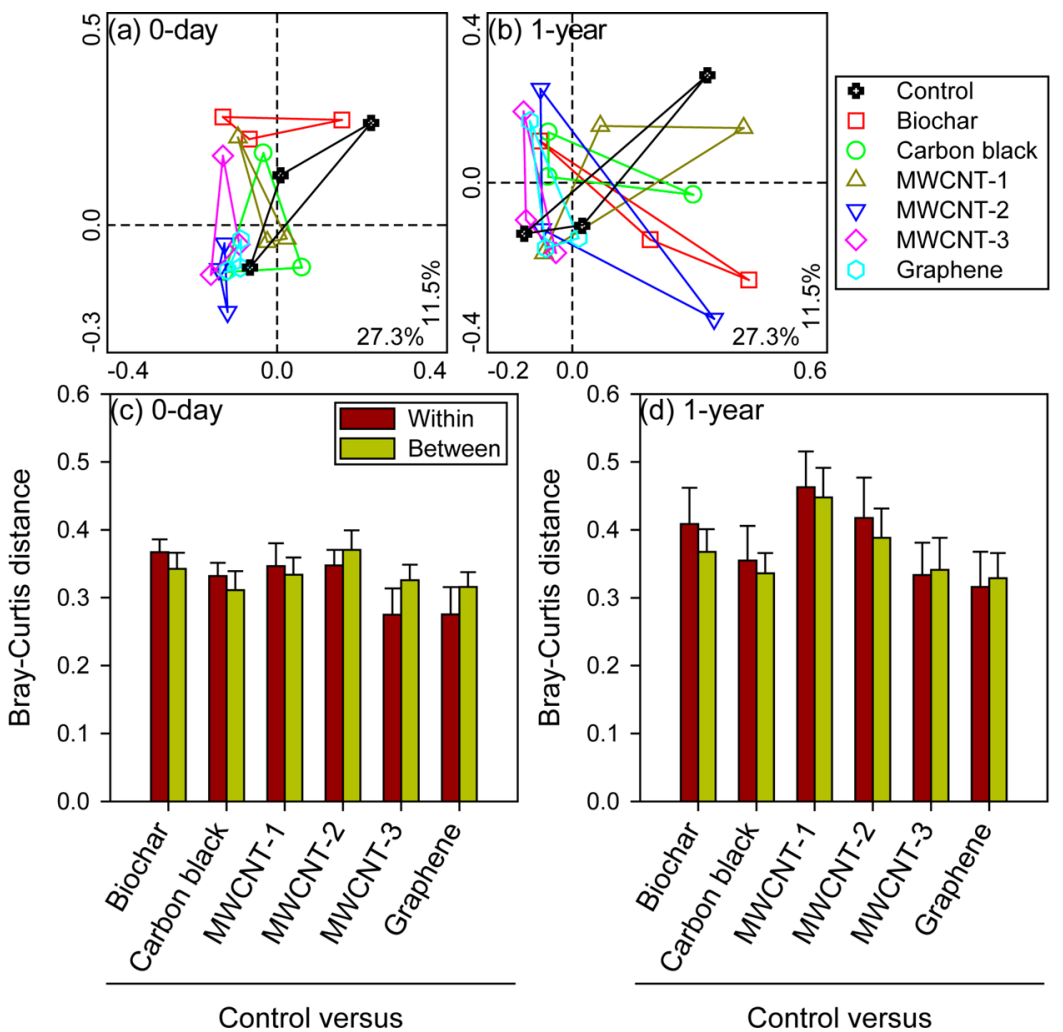

Figure 5. Treatment effects on soil fungal communities analyzed by terminal restriction fragment length polymorphism (T-RFLP) using HhaI digested PCR products: (a) fungal community variation after 0-day exposure; (b) fungal community variation after 1-year exposure; (c) comparisons of community dissimilarities within and between treatments after 0-day exposure; (d) comparisons of community dissimilarities within and between treatments after 1-year exposure. There was no significant treatment effect on soil fungal communities either after 0-day or after 1-year exposure. Error bars indicate the standard error of the mean $(n=3)$.

restriction enzyme HhaI was first used to digest fungal PCR products for T-RFLP analysis; HhaI is often used for fungal TRFLP analysis. ${ }^{16,41}$ However, there was no significant treatment effect on HhaI-digested fungal T-RFLP profiles after 0-day and 1 -year exposures, as reflected by both the PCoA graphs (Figure $5 \mathrm{a}, \mathrm{b})$ and the comparisons of community dissimilarities within and between treatments $(P>0.05$ for all pairs, Figure $5 c, d)$. Since no effect was observed, we questioned whether the restriction enzyme HhaI was unable to differentiate the treatment effects on soil fungal communities in our soil samples. Therefore, we used another widely used restriction enzyme MspI to digest fungal PCR products for T-RFLP analysis. ${ }^{16,41}$ We still found that the treatments did not affect MspI-digested fungal T-RFLP profiles after 0-day and 1-year exposures (Figure S2). Furthermore, a Mantel test confirmed the significant correlation $(R=0.87, P<0.05)$ between the two T-RFLP profiles derived from HhaI- and MspI-digested fungal PCR products (Figure 6). Since both analyses acquired similar results and both T-RFLP profiles were significantly correlated, the observation of no treatment effect on soil fungal communities should be true, rather than due to a methodological bias. Therefore, the ECNMs examined in this study did not affect soil fungal community profiles after longterm exposure (1 year).

In a previous study, Rodrigues et al. found that fungal communities were altered in response to SWCNTs and remained different over 14 days. ${ }^{16}$ The different observations between studies may be partially attributed to differences in ECNM types, soil properties, associated communities, and experimental conditions. It is also possible that the fungal

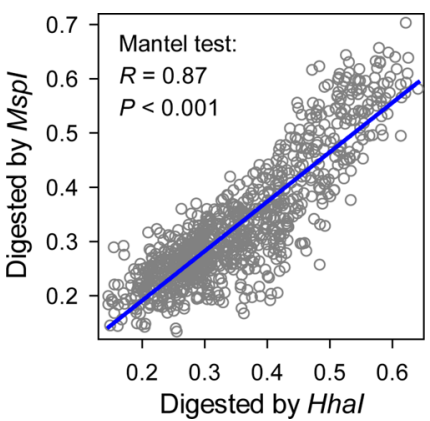

Figure 6. Significant correlation $(P<0.05)$ between two T-RFLP profiles derived from HhaI- and MspI-digested fungal PCR products.

communities herein recovered from ECNM stress during the long-term exposure. Possibly related, Rodrigues et al. reported that the major effects of SWCNTs on bacterial communities were observed after 3 days of exposure but that the bacterial communities recovered after 14 days. ${ }^{16}$ Although Rodrigues et al. did not observe the recovery of fungal communities during the 14-day exposure period, this may happen if the exposure period is extended. Therefore, our long-term exposure experiment may provide new information that is undiscoverable by short-term experiments.

Soil Basal Respiration (SBR). SBR was measured over the 1-year incubation for monitoring microbial activity under the different treatments (Figures 7 and S3). For all treatments, the SBR decreased rapidly at the beginning (Figure S3) and then slowed at the late stage of the incubation (Figure 7), which 


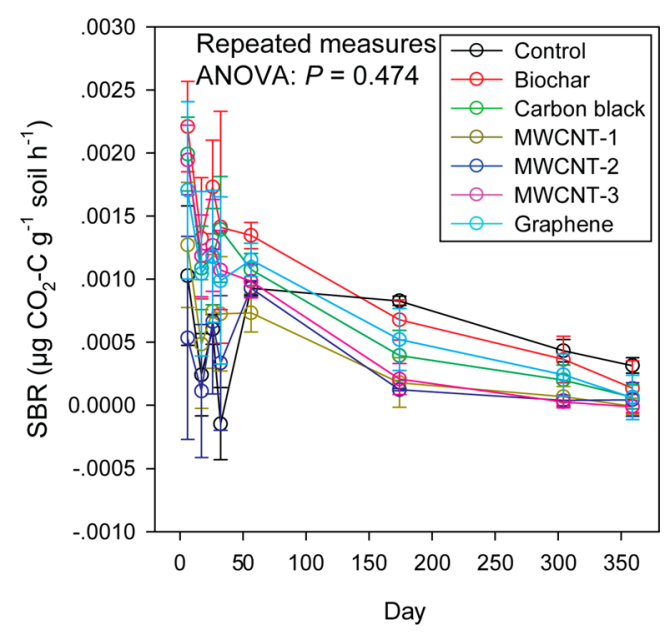

Figure 7. Treatment effects on soil basal respiration (SBR) over 1-year of incubation. SBR was not significantly different among treatments. Error bars indicate the standard error of the mean $(n=3)$.

represents a typical pattern for soil microbial respiration. ${ }^{54}$ In this study, because we aimed to maintain natural soil conditions and thus incubated microcosms without any water addition, the soils were dry (water content $5 \%$ ). In a previous study, soils also sampled from the Sedgwick Natural Reserve site were actively respiring under similarly dry conditions, possibly due to continued exoenzyme activity and viable microbial activity. ${ }^{54}$ Further, in a prior study with nano- $\mathrm{TiO}_{2}$ amended to these soils regarding interactive effects of nanomaterials and soil water potential, the lowest (ca. 7\%) moisture content condition maintained viable bacterial communities over a 9 month exposure. $^{27}$ Therefore, although the soils used in this study were quite dry, the microorganisms in the soils were still viable over the time of the experiment, and thus if the amended materials had been differentially bioavailable and/or toxic, the microorganisms would have been differentially affected. However, repeated measures ANOVA showed that SBR was not significantly different among treatments across all time points $(P=0.529$, Figure 7$)$, indicating that the amended materials had limited effects on soil microbial activity.

In summary, this study examined the long-term effects of three MWCNTs and graphene on dry soil microbial communities, in the context of comparing to not only the ECNM-free control but also to two widely used natural and industrial carbonaceous materials: biochar and carbon black. Our findings provide insights into the terrestrial effects of ECNMs in a manner that newly explores whether the effects caused by ECNMs differ from those caused by biochar and carbon black, which are intentionally or uncontrollably directed to soils. The 1-year exposure distinguishes our study from previously published studies and thus provides new data for understanding long-term ECNM effects. Further, since soil is a vehicle for exposing multiple taxa at once to ECNMs, assessing soil community effects assists with interpreting single taxa exposure studies ${ }^{9,11}$ in the context of interacting with other taxa including those not cultured. We found that some ECNMs (e.g., narrow MWCNT and graphene) reduced soil DNA and induced bacterial community shifts when compared to the ECNM-free control. However, when compared to the natural and industrial carbonaceous materials (biochar and carbon black), none of the ECNMs examined in this study (three MWCNTs and graphene) significantly changed soil microbial biomass (by extractable DNA and SIR), bacterial communities (by T-RFLP), fungal communities (by T-RFLP), and microbial respiration. Comparing effects of ECNMs to the widely used natural and industrial carbonaceous materials such as biochar and carbon black could provide powerful information upon which to benchmark regulatory decisions regarding possible ecological effects of engineered nanomaterials. Carbon black has recently been re-evaluated for its ecotoxicology and deemed relatively nontoxic and nonbioaccumulative. ${ }^{32}$ Thus, because of its material similarity to ECNMs, CB is a useful negative ecotoxicological control which conceptually parallels human health-oriented toxicological studies that compare MWCNTs to relatively low toxicity $\mathrm{CB} .{ }^{55}$ Essentially, to the degree that the ECNMs evaluated in this study were no different in their effects on soil microbial communities as compared to widespread carbon black or nanostructured biochar soil amendments, regulatory concerns-specifically for biological receptors and conditions as tested here-might be directed elsewhere.

\section{ASSOCIATED CONTENT}

\section{Supporting Information}

The Supporting Information is available free of charge on the ACS Publications website at DOI: 10.1021/acs.est.5b05620.

Correlation between SIR and extractable DNA (Figure S1), treatment effects on soil fungal communities analyzed by terminal restriction fragment length polymorphism (T-RFLP) using MspI digested PCR products (Figure S2), treatment effects on soil basal respiration (SBR) early in the incubation (Figure S3), and material properties reported by Cheap Tubes (Table S1) (PDF)

\section{AUTHOR INFORMATION}

\section{Corresponding Author}

*Phone: 805-893-3195. Fax: 805-893-7612. E-mail: holden@ bren.ucsb.edu.

\section{Author Contributions}

The manuscript was written through contributions of all authors. All authors have given approval to the final version of the manuscript.

\section{Notes}

The authors declare no competing financial interest.

\section{ACKNOWLEDGMENTS}

This work was supported by the National Science Foundation and the Environmental Protection Agency under Cooperative Agreement DBI-0830117. Any opinions, findings, and conclusions are those of the authors and do not necessarily reflect the views of the National Science Foundation or the Environmental Protection Agency. This work has not been subjected to EPA review and no official endorsement should be inferred. This project was additionally supported by funds from the trust of Mr. Henry H. Wheeler, Jr. M.M. acknowledges support from the Estonian Research Council grant PUTJD16. We acknowledge the Sedgwick Natural Reserve of the UCSB Natural Reserve System for providing the soil used in this study.

\section{REFERENCES}

(1) De Volder, M. F. L.; Tawfick, S. H.; Baughman, R. H.; Hart, A. J. Carbon nanotubes: present and future commercial applications. Science 2013, 339 (6119), 535-539. 
(2) Klaine, S. J.; Alvarez, P. J. J.; Batley, G. E.; Fernandes, T. F.; Handy, R. D.; Lyon, D. Y.; Mahendra, S.; McLaughlin, M. J.; Lead, J. R. Nanomaterials in the environment: behavior, fate, bioavailability, and effects. Environ. Toxicol. Chem. 2008, 27 (9), 1825-1851.

(3) Zhao, Q.; Yang, K.; Li, W.; Xing, B. Concentration-dependent polyparameter linear free energy relationships to predict organic compound sorption on carbon nanotubes. Sci. Rep. 2014, 4, 3888.

(4) Keller, A.; McFerran, S.; Lazareva, A.; Suh, S. Global life cycle releases of engineered nanomaterials. J. Nanopart. Res. 2013, 15 (6), 1692.

(5) Petersen, E. J.; Zhang, L.; Mattison, N. T.; O'Carroll, D. M.; Whelton, A. J.; Uddin, N.; Nguyen, T.; Huang, Q.; Henry, T. B.; Holbrook, R. D.; Chen, K. L. Potential release pathways, environmental fate, and ecological risks of carbon nanotubes. Environ. Sci. Technol. 2011, 45 (23), 9837-9856.

(6) Turco, R. F.; Bischoff, M.; Tong, Z. H.; Nies, L. Environmental implications of nanomaterials: are we studying the right thing? Curr. Opin. Biotechnol. 2011, 22 (4), 527-532.

(7) Holden, P. A.; Nisbet, R. M.; Lenihan, H. S.; Miller, R. J.; Cherr, G. N.; Schimel, J. P.; Gardea-Torresdey, J. L. Ecological nanotoxicology: integrating nanomaterial hazard considerations across the subcellular, population, community, and ecosystems levels. Acc. Chem. Res. 2013, 46 (3), 813-822.

(8) Holden, P. A.; Schimel, J. P.; Godwin, H. A. Five reasons to use bacteria when assessing manufactured nanomaterial environmental hazards and fates. Curr. Opin. Biotechnol. 2014, 27, 73-78.

(9) Rodrigues, D. F.; Elimelech, M. Toxic effects of single-walled carbon nanotubes in the development of E. coli biofilm. Environ. Sci. Technol. 2010, 44 (12), 4583-4589.

(10) Zhu, B.; Xia, X.; Xia, N.; Zhang, S.; Guo, X. Modification of fatty acids in membranes of bacteria: implication for an adaptive mechanism to the toxicity of carbon nanotubes. Environ. Sci. Technol. 2014, 48 (7), 4086-4095.

(11) Yan, F.-F.; He, Y.-R.; Wu, C.; Cheng, Y.-Y.; Li, W.-W.; Yu, H.-Q. Carbon nanotubes alter the electron flow route and enhance nitrobenzene reduction by Shewanella oneidensis MR-1. Environ. Sci. Technol. Lett. 2014, 1 (1), 128-132.

(12) Johansen, A.; Pedersen, A. L.; Jensen, K. A.; Karlson, U.; Hansen, B. M.; Scott-Fordsmand, J. J.; Winding, A. Effects of $\mathrm{C}_{60}$ fullerene nanoparticles on soil bacteria and protozoans. Environ. Toxicol. Chem. 2008, 27 (9), 1895-1903.

(13) Tong, Z.; Bischoff, M.; Nies, L.; Applegate, B.; Turco, R. F. Impact of fullerene $\left(\mathrm{C}_{60}\right)$ on a soil microbial community. Environ. Sci. Technol. 2007, 41 (8), 2985-2991.

(14) Jin, L.; Son, Y.; DeForest, J. L.; Kang, Y. J.; Kim, W.; Chung, H. Single-walled carbon nanotubes alter soil microbial community composition. Sci. Total Environ. 2014, 466-467, 533-538.

(15) Jin, L.; Son, Y.; Yoon, T. K.; Kang, Y. J.; Kim, W.; Chung, H. High concentrations of single-walled carbon nanotubes lower soil enzyme activity and microbial biomass. Ecotoxicol. Environ. Saf. 2013, $88,9-15$.

(16) Rodrigues, D. F.; Jaisi, D. P.; Elimelech, M. Toxicity of functionalized single-walled carbon nanotubes on soil microbial communities: implications for nutrient cycling in soil. Environ. Sci. Technol. 2013, 47 (1), 625-633.

(17) Tong, Z.; Bischoff, M.; Nies, L. F.; Myer, P.; Applegate, B.; Turco, R. F. Response of soil microorganisms to as-produced and functionalized single-wall carbon nanotubes (SWNTs). Environ. Sci. Technol. 2012, 46 (24), 13471-13479.

(18) Chung, H.; Son, Y.; Yoon, T. K.; Kim, S.; Kim, W. The effect of multi-walled carbon nanotubes on soil microbial activity. Ecotoxicol. Environ. Saf. 2011, 74 (4), 569-575.

(19) Khodakovskaya, M. V.; Kim, B.-S.; Kim, J. N.; Alimohammadi, M.; Dervishi, E.; Mustafa, T.; Cernigla, C. E. Carbon nanotubes as plant growth regulators: effects on tomato growth, reproductive system, and soil microbial community. Small 2013, 9 (1), 115-123.

(20) Shrestha, B.; Acosta-Martinez, V.; Cox, S. B.; Green, M. J.; Li, S.; Cañas-Carrella, J. E. An evaluation of the impact of multiwalled carbon nanotubes on soil microbial community structure and functioning. J. Hazard. Mater. 2013, 261, 188-197.

(21) Ren, W.; Ren, G.; Teng, Y.; Li, Z.; Li, L. Time-dependent effect of graphene on the structure, abundance, and function of the soil bacterial community. J. Hazard. Mater. 2015, 297, 286-294.

(22) Zhang, L.; Petersen, E. J.; Habteselassie, M. Y.; Mao, L.; Huang, Q. Degradation of multiwall carbon nanotubes by bacteria. Environ. Pollut. 2013, 181 (0), 335-339.

(23) Schreiner, K. M.; Filley, T. R.; Blanchette, R. A.; Bowen, B. B.; Bolskar, R. D.; Hockaday, W. C.; Masiello, C. A.; Raebiger, J. W. White-rot basidiomycete-mediated decomposition of $\mathrm{C}_{60}$ fullerol. Environ. Sci. Technol. 2009, 43 (9), 3162-3168.

(24) Flores-Cervantes, D. X.; Maes, H. M.; Schäffer, A.; Hollender, J.; Kohler, H.-P. E. Slow biotransformation of carbon nanotubes by horseradish peroxidase. Environ. Sci. Technol. 2014, 48 (9), 48264834.

(25) Zhang, C.; Chen, W.; Alvarez, P. J. J. Manganese peroxidase degrades pristine but not surface-oxidized (carboxylated) single-walled carbon nanotubes. Environ. Sci. Technol. 2014, 48 (14), 7918-7923.

(26) Parks, A. N.; Chandler, G. T.; Ho, K. T.; Burgess, R. M.; Ferguson, P. L. Environmental biodegradability of $\left[{ }^{14} \mathrm{C}\right]$ single-walled carbon nanotubes by Trametes versicolor and natural microbial cultures found in New Bedford Harbor sediment and aerated wastewater treatment plant sludge. Environ. Toxicol. Chem. 2015, 34 (2), 247-251.

(27) Ge, Y.; Priester, J. H.; Van De Werfhorst, L. C.; Schimel, J. P.; Holden, P. A. Potential mechanisms and environmental controls of $\mathrm{TiO}_{2}$ nanoparticle effects on soil bacterial communities. Environ. Sci. Technol. 2013, 47 (24), 14411-14417.

(28) Ge, Y.; Schimel, J. P.; Holden, P. A. Evidence for negative effects of $\mathrm{TiO}_{2}$ and $\mathrm{ZnO}$ nanoparticles on soil bacterial communities. Environ. Sci. Technol. 2011, 45 (4), 1659-1664.

(29) Ge, Y.; Schimel, J. P.; Holden, P. A. Identification of soil bacteria susceptible to $\mathrm{TiO}_{2}$ and $\mathrm{ZnO}$ nanoparticles. Appl. Environ. Microbiol. 2012, 78 (18), 6749-6758.

(30) Priester, J. H.; Ge, Y.; Chang, V.; Stoimenov, P. K.; Schimel, J. P.; Stucky, G. D.; Holden, P. A. Assessing interactions of hydrophilic nanoscale $\mathrm{TiO}_{2}$ with soil water. J. Nanopart. Res. 2013, 15 (9), 1899.

(31) Holden, P. A.; Klaessig, F.; Turco, R. F.; Priester, J. H.; Rico, C. M.; Avila-Arias, H.; Mortimer, M.; Pacpaco, K.; Gardea-Torresdey, J. L. Evaluation of exposure concentrations used in assessing manufactured nanomaterial environmental hazards: are they relevant? Environ. Sci. Technol. 2014, 48 (18), 10541-10551.

(32) Screening Assessment for the Challenge Carbon Black; Environment Canada Health: Canada, 2013.

(33) Zhao, J.; Wang, Z.; White, J. C.; Xing, B. Graphene in the aquatic environment: adsorption, dispersion, toxicity and transformation. Environ. Sci. Technol. 2014, 48 (17), 9995-10009.

(34) Brunauer, S.; Emmett, P. H.; Teller, E. Adsorption of gases in multimolecular layers. J. Am. Chem. Soc. 1938, 60 (2), 309-319.

(35) Anderson, J. P. E.; Domsch, K. H. A physiological method for the quantitative measurement of microbial biomass in soils. Soil Biol. Biochem. 1978, 10 (3), 215-221.

(36) West, A. W.; Sparling, G. P. Modifications to the substrateinduced respiration method to permit measurement of microbial biomass in soils of differing water contents. J. Microbiol. Methods 1986, 5 (3-4), 177-189.

(37) Aoshima, H.; Kimura, A.; Shibutani, A.; Okada, C.; Matsumiya, Y.; Kubo, M. Evaluation of soil bacterial biomass using environmental DNA extracted by slow-stirring method. Appl. Microbiol. Biotechnol. 2006, 71 (6), 875-880.

(38) Marstorp, H.; Guan, X.; Gong, P. Relationship between dsDNA, chloroform labile $\mathrm{C}$ and ergosterol in soils of different organic matter contents and pH. Soil Biol. Biochem. 2000, 32 (6), 879-882.

(39) Fierer, N.; Jackson, R. B. The diversity and biogeography of soil bacterial communities. Proc. Natl. Acad. Sci. U. S. A. 2006, 103 (3), $626-631$

(40) Cao, Y.; Green, P. G.; Holden, P. A. Microbial community composition and denitrifying enzyme activities in salt marsh sediments. Appl. Environ. Microbiol. 2008, 74 (24), 7585-7595. 
(41) Singh, B. K.; Nazaries, L.; Munro, S.; Anderson, I. C.; Campbell, C. D. Multiplex-terminal restriction fragment length polymorphism for rapid and simultaneous analysis of different components of the soil microbial community. Appl. Environ. Microbiol. 2006, 72 (11), 72787285.

(42) Ge, Y.; Priester, J. H.; Van De Werfhorst, L. C.; Walker, S. L.; Nisbet, R. M.; An, Y.-J.; Schimel, J. P.; Gardea-Torresdey, J. L.; Holden, P. A. Soybean plants modify metal oxide nanoparticle effects on soil bacterial communities. Environ. Sci. Technol. 2014, 48 (22), 13489-13496.

(43) Rees, G. N.; Baldwin, D. S.; Watson, G. O.; Perryman, S.; Nielsen, D. L. Ordination and significance testing of microbial community composition derived from terminal restriction fragment length polymorphisms: application of multivariate statistics. Antonie van Leeuwenhoek 2004, 86 (4), 339-347.

(44) Horst, A. M.; Vukanti, R; Priester, J. H.; Holden, P. A. An assessment of fluorescence- and absorbance-based assays to study metal-oxide nanoparticle ROS production and effects on bacterial membranes. Small 2013, 9 (9-10), 1753-1764.

(45) Petersen, E. J.; Henry, T. B.; Zhao, J.; MacCuspie, R. I.; Kirschling, T. L.; Dobrovolskaia, M. A.; Hackley, V.; Xing, B.; White, J. C. Identification and avoidance of potential artifacts and misinterpretations in nanomaterial ecotoxicity measurements. Environ. Sci. Technol. 2014, 48 (8), 4226-4246.

(46) Blagodatskaya, E. V.; Blagodatskii, S. A.; Anderson, T. H. Quantitative isolation of microbial DNA from different types of soils of natural and agricultural ecosystems. Microbiology 2003, 72 (6), 744749.

(47) Niemeyer, J.; Gessler, F. Determination of free DNA in soils. J. Plant Nutr. Soil Sci. 2002, 165 (2), 121-124.

(48) Steinberger, R. E.; Holden, P. A. Extracellular DNA in singleand multiple-species unsaturated biofilms. Appl. Environ. Microbiol. 2005, 71 (9), 5404-5410.

(49) Zimmerman, A. R; Gao, B.; Ahn, M.-Y. Positive and negative carbon mineralization priming effects among a variety of biocharamended soils. Soil Biol. Biochem. 2011, 43 (6), 1169-1179.

(50) Lehmann, J.; Rillig, M. C.; Thies, J.; Masiello, C. A.; Hockaday, W. C.; Crowley, D. Biochar effects on soil biota - a review. Soil Biol. Biochem. 2011, 43 (9), 1812-1836.

(51) Dempster, D. N.; Gleeson, D. B.; Solaiman, Z. M.; Jones, D. L.; Murphy, D. V. Decreased soil microbial biomass and nitrogen mineralisation with Eucalyptus biochar addition to a coarse textured soil. Plant Soil 2012, 354 (1-2), 311-324.

(52) Holden, P. A. How do the microhabitats framed by soil structure impact soil bacteria and the processes that they regulate? In The Architecture and Biology of Soils: Life in Inner Space; Ritz, K., Young, I., Eds.; CABI: Oxfordshire, 2011; pp 118-148.

(53) Harris, R. F. Effect of water potential on microbial growth and activity. In Water Potential Relations in Soil Microbiology, SSSA Special Publication Number 9; Parr, J. F., Gardner, W. R., Elliott, L. F., Eds.; Soil Science Society of America: Madison, WI, 1981; pp 23-95.

(54) Xiang, S.-R.; Doyle, A.; Holden, P. A.; Schimel, J. P. Drying and rewetting effects on $\mathrm{C}$ and $\mathrm{N}$ mineralization and microbial activity in surface and subsurface California grassland soils. Soil Biol. Biochem. 2008, 40 (9), 2281-2289.

(55) Oberdörster, G.; Castranova, V.; Asgharian, B.; Sayre, P. Inhalation exposure to carbon nanotubes (CNT) and carbon nanofibers (CNF): methodology and dosimetry. J. Toxicol. Environ. Health, Part B 2015, 18 (3-4), 121-212. 